Article

\title{
Ambient Pressure Laser Desorption-Chemical Ionization Mass Spectrometry for Fast and Reliable Detection of Explosives, Drugs, and Their Precursors
}

\author{
René Reiss ${ }^{1}$, Sven Ehlert ${ }^{1}$, Jan Heide ${ }^{1}$, Michael Pütz ${ }^{2}$, Thomas Forster ${ }^{2}$ \\ and Ralf Zimmermann ${ }^{1,3, *}$ \\ 1 Joint Mass Spectrometry Centre, Chair of Analytical Chemistry, University of Rostock, \\ Dr.-Lorenz-Weg 2, 18059 Rostock, Germany; rene.reiss@uni-rostock.de (R.R.); \\ sven.ehlert@uni-rostock.de (S.E.); jan.heide@uni-rostock.de (J.H.) \\ 2 Bundeskriminalamt-Federal Criminal Police Office (BKA), Forensic Science Institute, Äppelallee 45, \\ 65203 Wiesbaden, Germany; Michael.Puetz@bka.bund.de (M.P.); Thomas.Forster@bka.bund.de (T.F.) \\ 3 Joint Mass Spectrometry Centre, Comprehensive Molecular Analytics, Helmholtz Zentrum München, \\ Ingolstädter Landstr. 1, 85764 Neuherberg, Germany \\ * Correspondence: ralf.zimmermann@helmholtz-muenchen.de; Tel.: +49-381-498-6460
}

Received: 6 May 2018; Accepted: 2 June 2018; Published: 5 June 2018

Featured Application: Direct detection of safety relevant, low volatile substances on surfaces, ranging from tableted drugs to suspicious remnants on surfaces like bags, luggage, or even containers.

\begin{abstract}
Fast and reliable information is crucial for first responders to draw correct conclusions at crime scenes. An ambient pressure laser desorption (APLD) mass spectrometer is introduced for this scenario, which enables detecting substances on surfaces without sample pretreatment. It is especially useful for substances with low vapor pressure and thermolabile ones. The APLD allows for the separation of desorption and ionization into two steps and, therefore, both can be optimized separately. Within this work, an improved version of the developed system is shown that achieves limits of detection (LOD) down to $500 \mathrm{pg}$ while remaining fast and flexible. Furthermore, realistic scenarios are applied to prove the usability of this system in real-world issues. For this purpose, post-blast residues of a bomb from the Second World War were analyzed, and the presence of PETN was proven without sample pretreatment. In addition, the analyzable substance range could be expanded by various drugs and drug precursors. Thus, the presented instrumentation can be utilized for an increased number of forensically important compound classes without changing the setup. Drug precursors revealed a LOD ranging from 6 to $100 \mathrm{ng}$. Drugs such as cocaine hydrochloride, heroin, (3,4-methylendioxy-methamphetamine) hydrochloride (MDMA) hydrochloride, and others exhibit a LOD between 10 to $200 \mathrm{ng}$.
\end{abstract}

Keywords: APLD; drugs; explosives; post blast residue detection; mass spectrometry; chemical ionization; on-line measurement; forensic chemistry; mapping

\section{Introduction}

In real-world scenarios, the fast and selective detection of security-relevant substances can be crucial to ensure the most appropriate decision is taken as a foundation for further tactical procedures and minimization of risk for first responders and the civil population. In addition to other approaches like ion mobility spectrometry, mass spectrometry (MS) has been proven as a powerful and versatile technique to detect such substances. There are some MS techniques that should be mentioned, especially when focusing on explosives. In particular, gas chromatography coupled to 
mass spectrometry (GC-MS) has to be mentioned as a lab based technique and is used for more than 40 years to detect explosives and is a still improving field [1-6]. Besides an increase of reliability due to chromatographic separation, some mass spectrometers allow selective ion fragmentation of potential target substance to prove identification. This so-called tandem mass spectrometry function increases significantly the probability of a correct positive detection result and enables a lower false alarm rate, e.g., at luggage checks on airports. Ion trap (IT) mass spectrometers equipped with different ionization techniques are commonly deployed for such tandem mass spectrometric experiments. Depending on the analytical target, most IT-MS can be equipped with different ionization techniques like electron ionization (EI), chemical ionization (CI) [7], or single photon ionization (SPI) [8]. Surface analyzing techniques allow for the observation of different potentially interesting targets in forensic science like luggage, letters, or clothes without time-consuming sample pretreatment. Direct analyses in real time (DART) [9,10], DART-Raman combination [11], desorption electrospray ionization (DESI) [12,13], solvent assisted desorption/ionization mass spectrometry (DI-MS) [14], or a variety of laser desorption/ionization (LDI) [15] systems are common techniques. Two of the most famous setups of these LDI systems are called matrix-assisted laser desorption/ionization (MALDI) $[16,17]$ and surface-assisted laser desorption/ionization (SALDI) $[10,18]$. Omitting a special matrix and directly using the surface where a sample is located leads to the so called direct LDI approach. If interesting spots on bulky objects like containers, bulky luggage, or cars should be analyzed, highly mobile systems are preferable that can operate with a flexible sampling. Therefore, a separation of desorption and ionization processes can be beneficial because it allows a targeted optimization of the specific components to acquire enhanced results. One effective opportunity to realize the sampling is direct laser desorption (LD) that does not require additional media other than electricity. It is commonly used as the desorption step for various applications such as investigation of biological tissues [19-21], aerosols [22], pesticides [23], drugs [24], and explosives [25,26]. Drugs and explosives are relevant classes in forensic science. Explosives exhibit two characteristics that complicate their detection with common approaches but improves their applicability for LD: a very low vapor pressure, e.g., RDX (hexahydro-1,3,5-trinitro-1,3,5-triazine) has $4.4 \times 10^{-9} \mathrm{mPa}$ or HNS (hexanitrostilbene) with $6.2 \times 10^{-18} \mathrm{mPa}$ [27], and many of them are thermolabile. Some drugs also have a very low vapor pressure such as cocaine hydrochloride with $1.9 \times 10^{-3} \mathrm{mPa}$ or heroin hydrochloride with $1.2 \times 10^{-3} \mathrm{mPa}[28]$ and can be detected with this system even if they are not prone to a fast thermal degradation like explosives. By using a pulsed LD, instead of a continuous wave approach [29], thermal stress is lowered and leads to less fragmentation and better detection limits for explosives. Furthermore, a pulsed LD induces a shockwave-like ablation of the sample material from the surface and thus vapor pressure of the analyte is less crucial [29]. Some well-known and established vacuum ionization techniques that can be combined with LD are EI or CI. CI, for example, uses a reactant gas for a softer ionization [7]. Hence, spectra generated by CI mostly have fewer fragments and the quasi-molecular ion signal is more intense, which leads to easier interpretable spectra.

Recently, we suggested ambient pressure laser desorption (APLD) [30] in combination with CI [31] for different explosives and showed the advantages of this straightforward and field-deployable system. In particular, this design is considered as a benefit for on-site applications, because only electricity is required (and methane as reactant gas if $\mathrm{CI}$ is used). To enable the detection of even small amounts of analyte, it was attempted to improve the limit of detection. Therefore, improvements on the transfer system and the desorption unit are done in this work to further enhance the detection characteristics for different explosives and drug precursors. In addition, there are many other substances that are of potential interest in the forensic field and that could also benefit from the APLD. Because of this, we would like to show that the APLD is not limited to explosives but also allows for the measuring of drugs and drug precursors at a comparable level to other measurement techniques. This greatly enhances the versatility of this technique because it enables it to cover different forensically-relevant compound classes with a single system. A practical example could be the rapid search of containers for smuggled synthetic drug precursors in container ports. 


\section{Materials and Methods}

Explosives, drugs, and drug precursors investigated in this study were obtained from the German Federal Criminal Police Office (BKA, Wiesbaden, Germany). Explosives were acquired as methanolic solutions with a concentration of $1 \mathrm{~g} / \mathrm{L}$ and drug precursors as well as ketamine as pure substances. Explosives were trinitrotoluene, 1,3-dinitrobenzene, 2,4-dinitrotoluene, 2,6-dinitrotoluene, 2,4,6-trinitrophenylmethyl-nitramine, picric acid, 3,4-dinitrotoluene, triacetonetriperoxide, and ammonia nitrate. Drug precursors/drugs of abuse were ketamine hydrochloride, safrole, amantadine, and phenylacetone. Some 5F-Cumyl-PINACA, a cannabimimetic new psychoactive substance, coated on herbal blend and sold as "Rollin' High" was also received from the BKA. Potassium chlorate was obtained from Sigma Aldrich Chemie GmbH (Steinheim, Germany) and potassium perchlorate anhydrous was bought at Thermo Fisher $\mathrm{GmbH}$ (Kandel, Germany). Used solvents were dichloromethane and methanol from Carl Roth GmbH + Co. KG (Karlsruhe, Germany). Methane 4.5 as CI reactant gas and helium 5.0 were bought from Linde AG (Berlin, Germany). A schematic overview of the system and its parts can be seen in Figure 1. This figure describes all relevant parts of the system and is explained in detail at the end of this chapter. A Minilite neodymium-doped yttrium aluminum garnet (Nd:YAG) laser from Continuum Inc. (San Jose, CA, USA) was used for desorption in the second harmonic wavelength $(\lambda=532 \mathrm{~nm})$. Mass spectra and software were acquired utilizing a Varian Inc. (Walnut Creek, CA, USA) ion trap 240-MS and Varian MS Workstation 6.9.1. The MS parameter for CI were a mass rage of 50 to $400 \mathrm{~m} / z, 1.7 \mathrm{~Hz}$ acquisition rate, $3 \mu \mathrm{s}$ cans averaged, $3 \mathrm{~mL} / \mathrm{min}$ helium cooling gas flow, and full scan for all measurements. For EI measurements, an acquisition rate of $0.8 \mathrm{~Hz}$ and an emission current of $25 \mu \mathrm{A}$ were chosen. Other MS parameters were similar to CI. Calibration was done for $\mathrm{EI}$ and $\mathrm{CI}$ with pure perfluorotributylamine, as required by the instrument. Lens energy and tuning was carried out automatically by MS software. Laser light was transferred from the laser to the ambient pressure desorption head with a $1250 \mu \mathrm{m}$ Optran UV laser fiber from CeramOptec GmbH (Bonn, Germany). The ambient pressure desorption head was self-built and made out of brass and polytetrafluoroethylene for thermal separation. A stainless steel capillary with $100 \mu \mathrm{m}$ inner diameter was used as the transfer-line and was bought at IDEX Health \& Science LLC (Oak Habor, WA, USA). Sample deposition on the sampling surface was done by a microliter syringe from Hamilton Bonaduz AG (Bonaduz, Switzerland). For automated and easy surface analysis, a self-build two-axis linear driving system (X-Y table) was combined with stepper motors and the MCC-2 stepper motor controller from Phytron GmbH (Gröbenzell, Germany). The sample desorption surface was a steel sheet made of V2A steel.

For sampling, $1 \mu \mathrm{L}$ aliquots were spotted directly onto the steel target; spots were dried under ambient conditions, and the residue carrying surface was placed on the X-Y table. The sample spots were as small as possible, with a maximum diameter of $1 \mathrm{~mm}$. Subsequently, the sample surface was scanned automatically with the APLD system until the residue was detected. Therefore, an area of $5 \times 5 \mathrm{~mm}$ was scanned to ensure the substance was hit. Each spot was desorbed with a single laser pulse every millimeter distance at a repetition rate of $10 \mathrm{~Hz}$. After all data was collected, the surface was cleaned with methanol and could be reused. The desorption head did not require further cleaning after a measurement. The APLD system was heated to $200^{\circ} \mathrm{C}$. For explosives and explosive precursors, negative detection mode was chosen. All other compounds were analyzed with positive detection mode. Due to the fact that ambient samples with high air intake were measured, $\mathrm{CI}$ with external ionization was realized. External ionization means that ions are formed outside the trap in a specific ionization region inside the mass spectrometer. Although, internal ionization would lead to better limits of detection (LOD), the mass resolution and mass accuracy would strongly decrease simultaneously due to higher amounts of air. External ionization is a compromise between sensitivity and mass resolution for direct sampling of target compounds in an environmental gas matrix. 


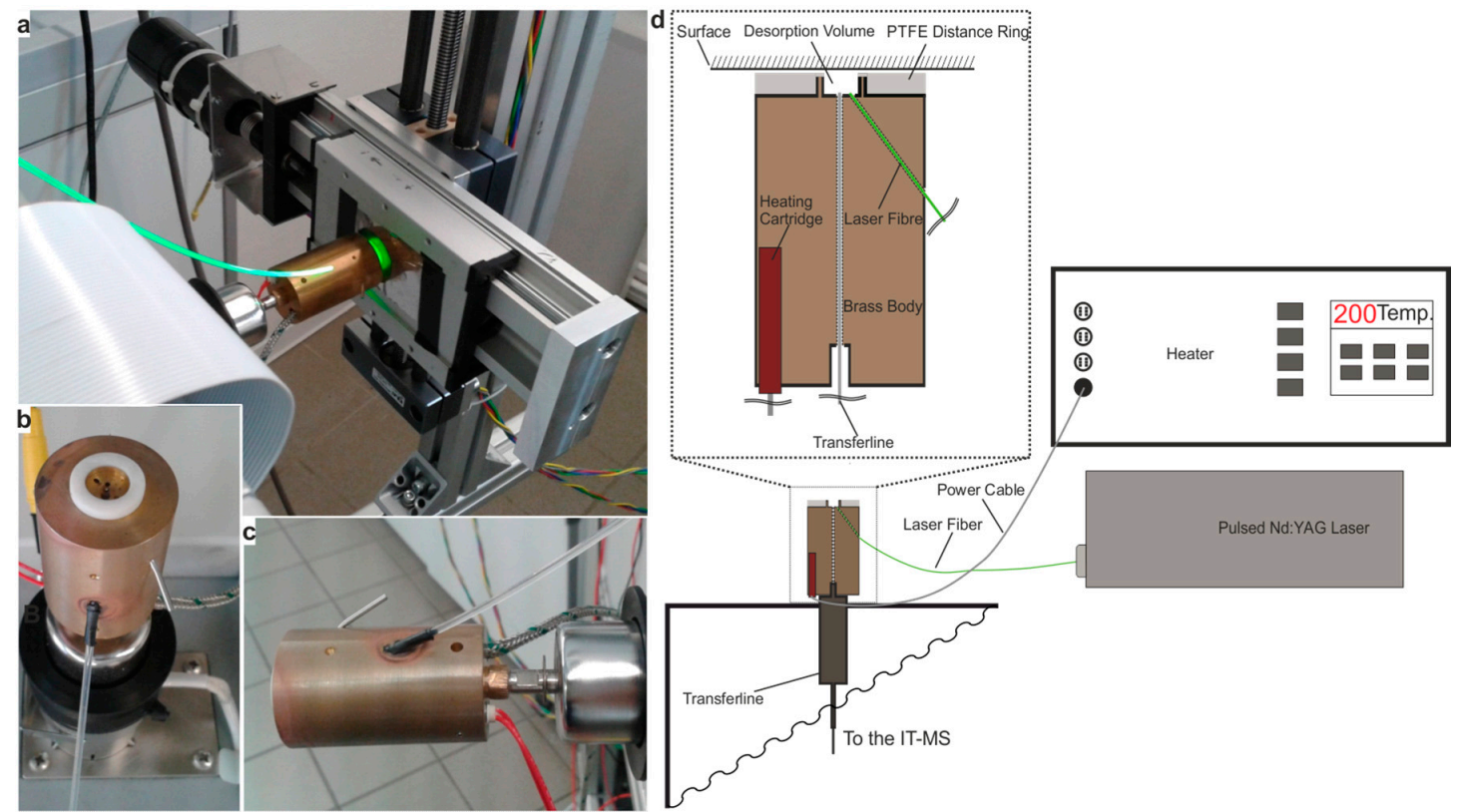

Figure 1. (a) Laser desorption sampling for mass spectrometric analysis from a stainless steel surface with a self-built X-Y table; (b) Deployed ambient pressure laser desorption (APLD) head with front view on desorption volume and polytetrafluoroethylene (PTFE) ring; (c) APLD head side view with attached laser fiber, heating cartridge, and thermocouple; (d) Schematic drawing of the APLD chemical ionization-mass spectrometer (APLD-CI-MS). The heating cartridge inside of the brass body ensures a complete heating of the sampling head. A laser fiber transfers pulsed laser light, produced by the Nd:YAG laser, to the surface. The ablated analyte is subsequently transferred into the transferline and afterwards into the IT-MS. There, it can be ionized by electron ionization (EI) or chemical ionization (CI) and then analyzed.

Real-world samples were held in front of the APLD, and the laser was activated. All settings were the same as for standard laboratory measurements. No cleaning was necessary after executed measurements.

The LOD is defined by a signal to noise ratio $(\mathrm{S} / \mathrm{N})$ of three. Therefore, the signal intensity was not extrapolated to an $\mathrm{S} / \mathrm{N}$ of three, instead it represents the lowest total amount of substance that was actually measured.

The ambient pressure laser desorption, shown in Figure 1, operates by direct desorption of samples from surfaces with short laser pulses. At first, an approximately $5 \mathrm{~ns}$ wide Nd:YAG laser pulse with a pulse energy of about $3-5 \mathrm{~mJ}$ was guided via a laser fiber to the sampling surface. The laser fiber was mounted at the desorption head with approximately three millimeters distance to the surface. The pulsed laser light ablated the analyte from the surface, and, subsequently, the ablated material was transferred through a capillary into the IT-MS. Desorption head and transfer capillary were heated to $200{ }^{\circ} \mathrm{C}$ to prevent unintended surface adsorption of analytes. Methane as reactant gas was used for chemical ionization, generating primarily protonated quasi molecular ions.

\section{Results and Discussion}

\subsection{Improved Detection Limits through Design Optimization}

We recently demonstrated in a previous work [31] an ambient pressure laser desorption system for the sensitive and flexible mass spectrometric detection of explosives. The detection limits were in a suitable range for forensic application as presented in this work. Nevertheless, an improved detection 
limit can enhance the reliability of the analytical method. In the original setup, a non-heated front end made out of polyether ether ketone (PEEK) was utilized.

In this study, several modifications to the existing system were performed. These modifications are the exchange of the type of material, establishing a heatable system, shortening the transferline, and increasing the laser fiber diameter. All these changes are discussed in the following section.

\subsubsection{Sampling Head Design Optimization}

The sampling head, crucial for a fast and sensitive detection, was modified first. The novel design, utilizing a heated brass body, was aimed to further improve the sampling. Within this modification, the brass area exposed to the analyte is minimized. Theoretically, imaginable catalytic surface processes can be neglected due to the fact that the analytes pass only a small brass surface area on their way into the transferline and only very few applications of brass for catalytic surface processes can be found [32]. Because of the minimized adsorption processes at the inside of this desorption head, a faster analyte transfer into the IT-MS is enabled. This in turn should give more narrow signals and better limits of detection. Heating of the investigated sample surface is prevented by mounting of a thin spacer of polytetrafluoroethylene (PTFE) at the top of the sampling head (Figure 1b). The influence of the transferline was investigated by varying the length and the diameter of the transferline while keeping the temperature and parameters constant. The diameter was adjusted to ensure a nearly similar sample flow into the MS. As exemplarily visualized in Figure 2 for the investigation of tetryl, the version with the shortened transferline revealed an approximately four-times improved signal width. This effect is caused by the higher temperature and a shorter transferline. On that account, a minimum of ad- and de-sorption within the transferline was achieved and thus more narrow peaks should be obtained.

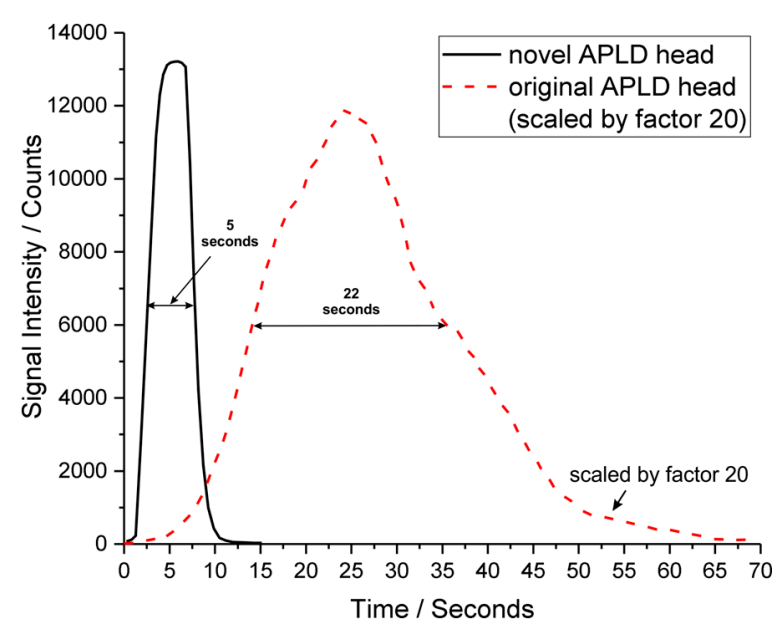

Figure 2. Compared smoothed desorption from spots with about $1.5 \mu \mathrm{g}$ Tetryl. Measured at negative CI mode and fragment $m / z$ 241. Novel system with short transferline and heated APLD head (solid line). Original measurement system with long transferline (dashed line). Compared is the full width at half maximum.

\subsubsection{Optimization of Desorption Area}

A further step that was implemented is the ability to use bigger laser fiber diameters at the same desorption volume inside the APLD head. By increasing the diameter of the laser fiber it is possible to transfer more laser light to the surface and simultaneously keeping the energy density constant. The diameter used before was about $0.6 \mathrm{~mm}$, while the new fiber has a $1.25 \mathrm{~mm}$ diameter and thus increased the desorption area by four times while retaining the same divergence angle of the laser fiber. Laser fluence of both systems ranged between 0.2 to $0.4 \mathrm{~J} / \mathrm{cm}^{2}$. This lead to a higher analyte concentration within the gaseous phase above the sample spot. 


\subsubsection{Optimization Results}

As can be seen in Figure 2, the full width at half maximum (FWHM) could be significantly decreased to about $5 \mathrm{~s}$ compared to $22 \mathrm{~s}$ with the original measurement system, reported previously [31]. Starting point was the rise of the detector signal. At both measurements, the data acquisition was not triggered by laser shots and absolute delay was not regarded due to the lack of influence to the LOD. The transferline length differed from $1.5 \mathrm{~m}$ for the original system to $0.25 \mathrm{~m}$ for the novel one. As a result, the length of the transferline contributed to the peak shape and subsequently to the system response time. A higher signal at shorter timescale was obtained that, in addition, should contribute to a lower limit of detection. Depending on the exact application and scenario, the system allows a flexible change of the transferline length to adjust for a more sensitive or more flexible analysis (reaching surfaces in narrow places). Therefore, it is a matter of priorities which option to choose. On the one hand, better peak widths of just a few seconds and faster analytical results can be obtained. On the other hand, more flexibility at surface sampling is achievable by using a longer transferline.

These changes lead to significant improvements in the limits of detection, and the obtained results are shown in Table 1. It summarizes different individually measured nitro aromatic and peroxide explosives, drugs, drug precursors, and their obtained LOD. All LOD are real measured signals and were determined with the same procedure (described in the materials and methods section) at the same mass spectrometer for both systems. As expected, the limit of detection was lowered by one order of magnitude, for e.g., down to $2 \mathrm{ng}$ tetryl in relation to $30 \mathrm{ng}$ from previous results. In addition, for other explosives, like dinitrotoluene (DNT) and trinitrotoluene (TNT), the detectable amounts could be lowered significantly: for TNT down into the picogram range.

Table 1. Comparison of original and novel APLD systems by use of limit of detection (LOD) for different individually determined explosives. All mentioned improvements were used for the novel APLD system. Old LODs are taken from [31]. Substances that have been detected as fragments are marked with an * and the $m / z$ fragment value. All other substances were detected as molecular ion signals. All substances were measured in negative detection mode.

\begin{tabular}{|c|c|c|c|}
\hline Substance Measured & LOD Original System & LOD Novel System & Structure \\
\hline TNT (trinitrotoluene) & $3 \mathrm{ng}$ & $500 \mathrm{pg}$ & \\
\hline 1,3-Dinitrobenzene & $6 \mathrm{ng}$ & $1.5 \mathrm{ng}$ & \\
\hline 2,4-DNT (Dinitrotoluene) & $3 \mathrm{ng}$ & $1.5 \mathrm{ng}$ & \\
\hline 2,6-DNT & $6 \mathrm{ng}$ & 2 ng & \\
\hline $\begin{array}{c}\text { Tetryl } \\
(2,4,6 \text {-trinitrophenylmethylnitramine }) * \\
m / z 241\end{array}$ & $30 \mathrm{ng}$ & $2 \mathrm{ng}$ & \\
\hline
\end{tabular}

\subsection{Target Compound Enhancement}

In addition, to gain a more comprehensive impression about this system, other common explosives, like picric acid and ammonia nitrate, were determined. As can be seen in Table 2, 
these explosives have a similar limit of detection of about $3 \mathrm{ng}$ to $80 \mathrm{ng}$. The only exception is TATP (acetone peroxide) with a detection limit of about $800 \mathrm{ng}$. This can be explained due to the high thermal instability of this peroxide explosive making TATP difficult to detect for many different analyzing techniques. TATP's quite high vapor pressure limits the lowest amount of substance that can be prepared for a measurement, because the time before TATP evaporates completely decreases with the decreasing amount of substance used. Furthermore, potassium perchlorate and potassium chlorate were investigated but could not be detected within the investigated range of up to $2000 \mathrm{ng}$.

Drug precursors were additionally chosen because they are regarded as important target compounds in forensic science as some are already regulated or may give evidence for illegal drug synthesis. The APLD allows someone to scan the outer surfaces of liquid containers for drug precursor substances, which could indicate drug synthesis in a clandestine laboratory. Beside drug precursors, drugs of abuse were investigated to enhance the system capability. Therefore, ketamine and amantadine were considered as model substances for drugs of abuse [33,34]. In this work, ketamine represents possible sedatives and amantadine possible stimulants. Table 2 summarizes the limits of detection for these different substance classes. It has been shown that the capability of detecting drug precursors as well as drugs of abuse ranges from about 10 to $100 \mathrm{ng}$ total substance amount compared to 0.5 to $800 \mathrm{ng}$ for explosives. Therefore, the APLD system is also capable of detecting these compound classes and can be helpful for fast and straightforward collection of information and clues. To perform a substantial experiment to test the probability of detection, new substance deposition methods are needed. The applied "droplet method" is limited for such kinds of experiments because it cannot be assured that the spot density is high enough to mimic an evenly covered test surface.

Beside drugs precursors and drugs of abuse, also common illegal drugs like cocaine or heroin were investigated. All of these measured drugs are illicit and are, therefore, common target compounds in the forensic field. As a result of these measurements, the LOD could be determined to be in the same range as the other compound classes. Most substances could be detected at less than $20 \mathrm{ng}$ absolute amount at the tested surface. While the LOD of real samples may differ substantially due to several effects, it should be interpreted as the lower operation range and a performance indicator. For real world samples, the LOD is less relevant because a yes or no answer is sufficient in most cases.

\subsection{Real Sample Measurements}

\subsubsection{Shrapnel of Defused Bomb}

Besides standard substances, samples from real-world scenarios were investigated to exploit the practical capabilities for forensic analysis. For this purpose, post-blast residues of a defused Second World War bomb are investigated. This bomb was defused by controlled explosion carried out by the Berlin Police. After the explosion, shrapnel were gathered up by hand, sent to our laboratory and stored in a cardboard box at room temperature inside the laboratory. This scenario is a good example of a real world scenario where only little information about the exploded bomb is available. No further information about the bomb is available because it was defused as part of a batch of old bombs.

Figure 3 shows the results of the investigation of one of the pictured shrapnel with the APLD system. In sum, four different shrapnel pieces were investigated and 2 to 4 locations per shrapnel measured. It turned out that all spectra exhibit a clear signal at $m / z 227$, which can be correlated to the molecular ion signal $\mathrm{M}^{-}$of TNT. The presence of TNT can be assumed by the observed signals in the lower mass spectrum including the molecular ion signal of TNT at $m / z 227$, as well as two significant signals of respective fragments. As a comparison, the embedded mass spectrum shows an additional measurement of a $10 \mathrm{ng}$ TNT standard sample measured under the same conditions. As can be observed in the mass spectrum, strong indications of TNT attached to the bomb shrapnel were found. In addition, fragmentation seems to be caused by the substrate. Therefore, results confirm that the APLD measurement system is not only suitable for laboratory measurements but also for answering realistic forensic questions. The APLD delivers valuable information about the used explosive. 
Moreover, even longer periods between the collection of samples and the related investigation seem to be acceptable.

Table 2. Limit of detection for different individually determined drug precursors, drugs, drugs of abuse, and some additional explosives measured with the novel APLD system. It is mutually assumed that the amount of substance is to be seen as a total amount and the sample spot is considered as totally desorbed at the measurement as described in the materials and methods section. Substances that have been detected as fragments are marked with an * along with the $m / z$ fragment value. All explosives were detected as molecular ion signals and all other substances as protonated molecular ions. All explosives were measured in negative detection mode, all other substances in positive detection mode.

\begin{tabular}{|c|c|c|}
\hline Substances Measured at Novel Systems & LOD & Structure \\
\hline \multicolumn{3}{|l|}{ Explosives } \\
\hline PA (picric acid) & $15 \mathrm{ng}$ & \\
\hline $3,4-\mathrm{DNT}$ & $3 \mathrm{ng}$ & \\
\hline TATP (triacetonetriperoxide) & $800 \mathrm{ng}$ & \\
\hline AN (ammonia nitrate) $*, m / z 63$ & $78 \mathrm{ng}$ & $\mathrm{NO}_{3}{ }^{-}$ \\
\hline \multicolumn{3}{|l|}{ Drug precursors } \\
\hline Safrole & $100 \mathrm{ng}$ & \\
\hline Phenylacetone & $50 \mathrm{ng}$ & \\
\hline \multicolumn{3}{|l|}{ Drugs/drugs of abuse } \\
\hline Amphetamine & $20 \mathrm{ng}$ & \\
\hline Methamphetamine & $10 \mathrm{ng}$ & \\
\hline MDMA (3,4-methylendioxy-methamphetamine) hydrochloride & $20 \mathrm{ng}$ & \\
\hline Heroin & $200 \mathrm{ng}$ & \\
\hline Cocaine hydrochloride & $17 \mathrm{ng}$ & \\
\hline Ketamine hydrochloride & $6 \mathrm{ng}$ & \\
\hline
\end{tabular}




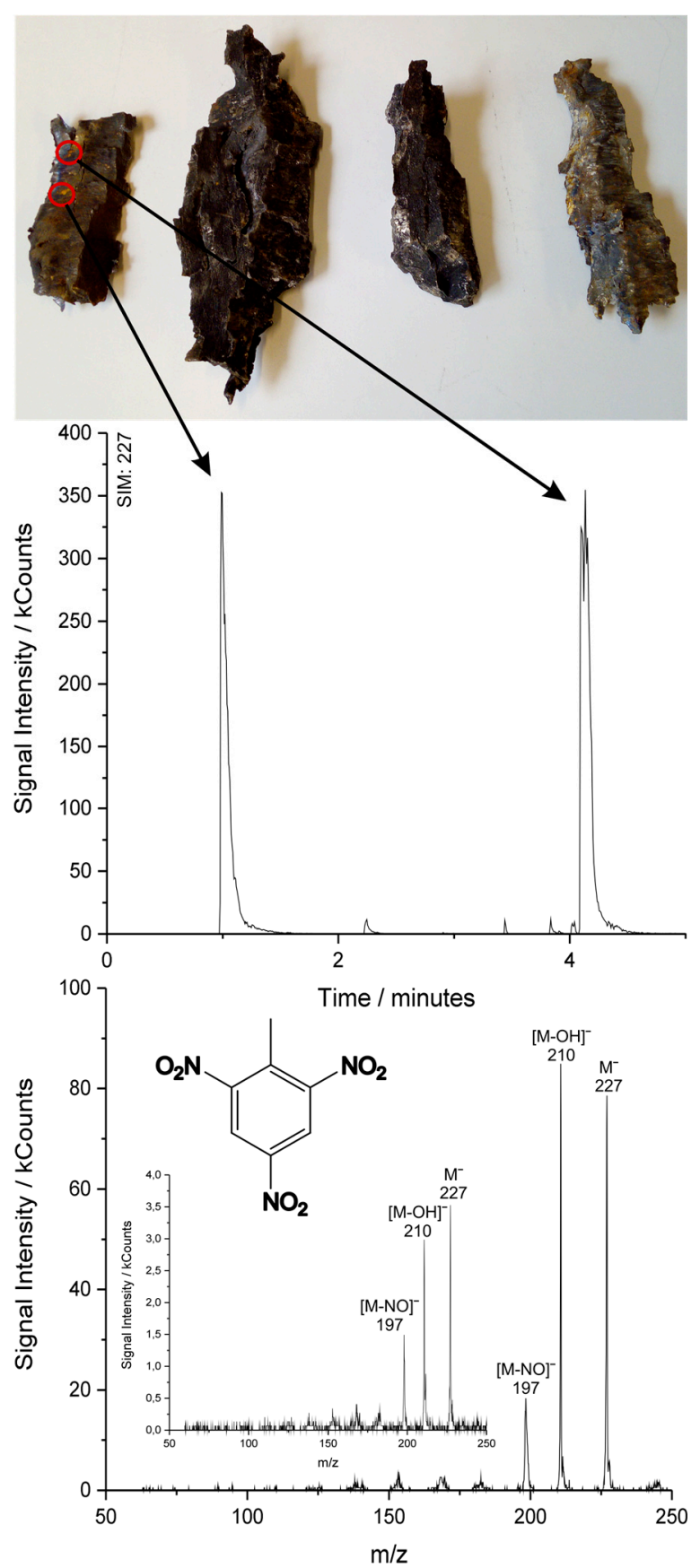

Figure 3. Desorption in negative CI mode of TNT from the surface of shrapnel recovered from a defused bomb of the Second World War. All shrapnel in the upper image show clear signals of TNT when investigated. A part of one of those single ion traces can be seen in the mass profile where the TNT signal at $m / z 227$ is plotted. The full size mass spectrum shows the first peak at about $1 \mathrm{~min}$. The panel in the lower left shows the spectrum of a $10 \mathrm{ng}$ TNT standard sample, measured under the same conditions. The signals look similar for every detected TNT trace and shrapnel.

\subsubsection{New Psychoactive Substance on Herbal Mixture}

Another practical application is illustrated in Figure 4. It shows the ability to detect synthetic cannabinoid species directly on herbal mixtures. These herbal blends are commonly coated with so-called new psychoactive substances (NPS). The investigated compound belongs to these NPS and is a cannabimimetic aminoalkyl indazole with a carboxamide-linked cumyl moiety (5F-Cumyl-PINACA). 
For better comparability and reliable substance identification, through fragment identification, EI, was applied as the ionization technique.

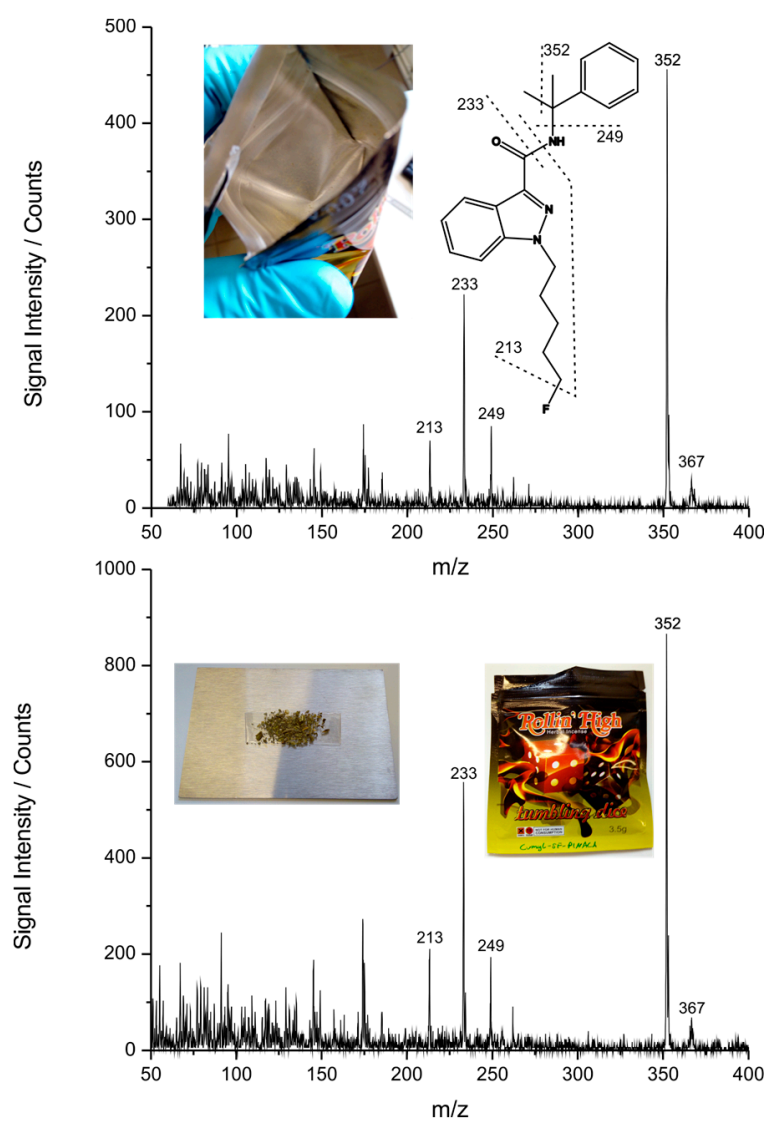

Figure 4. APLD EI-mass spectra of the herbal blend material. Direct laser desorption exhibits intense signals at higher $m / z$, tentatively assigned to 5F-Cumyl-PINACA from an herbal blend sold as "Rollin' High". This new psychoactive substance could be detected directly from herbal blend as well as residues sticking on the bag. The upper part shows a mass spectrum achieved by desorbing the inner side of the bag and the lower one a direct measurement of the herbal blend. A similar spectrum compared to the inside of the empty bag is revealed.

Strong EI fragmentation signal at low $m / z$ are typical when investigating complex natural samples. Direct measurement of the investigated herbal mixture revealed the usage of 5F-Cumyl-PINACA as an active substance at $m / z 367$ by comparing the molecular ion signal as well as the fragment pattern [35]. For direct measurement of the herbal mixture, a S/N ratio of 50.9 was calculated for the base peak at $\mathrm{m} / z 352$ and a $/ \mathrm{N}$ ratio of 3.7 for the molecular ion signal at $m / z 367$. For the respective measurement of the emptied bag, the $\mathrm{S} / \mathrm{N}$ ratio for the base peak at $m / z 352$ was 45.6 and for the molecular ion signal at $m / z 367$ the $\mathrm{S} / \mathrm{N}$ ratio was 3.1. Even an emptied bag, in which the mixture was sold, showed a clear presence of 5F-Cumyl-PINACA. Therefore, a fast decision can be made whether the target substance is illicit or not simply by measuring suspect or confiscated objects. A reasonable scenario could be the rapid identification of designer drugs and related products found in conspicuous parcels in postal distribution centers.

\subsection{Additional Capabilities of the APLD Approach}

The LODs and the measurement speed of the APLD system allows not only for the measurement of samples on surfaces at trace levels, but it also enables an automated measurement of surfaces without sample pretreatment. For this purpose, a computer controlled X-Y table was mounted in 
front of the APLD head. In consequence, the automated mapping of flat surfaces can be performed, which reveals APLD spectra with sub-millimeter lateral resolution. Analysis of non-flat surfaces could be difficult due to delocalization of target compounds by touching the PTFE ring. The actual system performance is illustrated in Figure 5. This figure shows the possibility to detect the spatial distribution of an artificially prepared substance trace on a surface. An imaginable scenario in context of a preliminary investigation that benefits from APLD capabilities could be the analysis of fingerprint residues from plastic explosives. In this case, the identification can be challenging due to the strong presence of matrix signals in the plastic explosive.

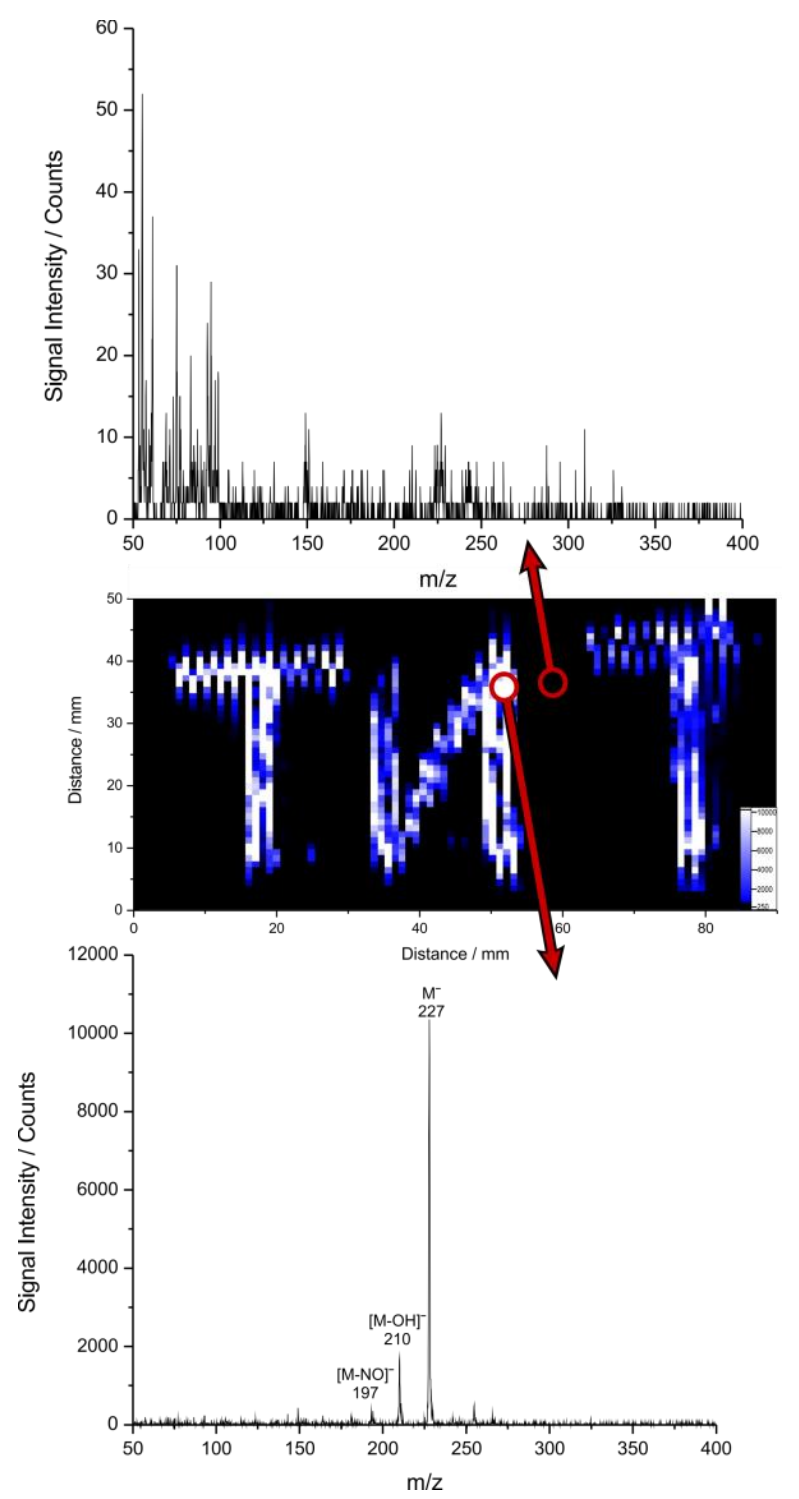

Figure 5. APLD mapping capabilities shown at a TNT example generated with CI negative detection mode. Two typical mass spectra can be seen above. If the position of the $X-Y$ table and the signal intensity is combined at any point of the surface the image on the top right can be achieved. This image shows a prepared stainless steel surface that was labeled with the word TNT. This label was produced with $1 \mathrm{mg} / \mathrm{L}$ TNT solution and a $\mu \mathrm{L}$ syringe. The total amount of substance applied for this image was about $20 \mu \mathrm{g}$. The color changes from black (no TNT detected) to white (high amounts of TNT detected). Therefore, the upper spectrum indicates a "black" area and the lower spectrum reveals the basis for a "white area". For mapping purposes a LabVIEW TM script was created, which can be found in the Supplementary Material. 
Comparing APLD to other analytical techniques that are available to detect directly trace levels of security relevant substances like explosives, drugs, or drug precursors leads to similar results regarding the LODs, ranging mostly in the low nanogram scale. Table 3 summaries compared analytical techniques and achieved LODs. In detail, the APLD allows similar LODs compared to Raman spectroscopy [36], ion mobility spectrometry [37], and thermal desorption (TD) MS [38,39]. Compared to APLD, desorption spray ionization (DESI) achieves better LODs for explosives [40] with the disadvantage of a more complex setup and the need of a liquid solvent supply. The LOD for TNT with DESI is about $10 \mathrm{fg}$. The achieved LODs for amphetamine using DESI is about $14 \mathrm{ng}$ compared to 20 ng using APLD [41]. The low-temperature plasma (LTP) probe [42] methodology behaves similarly to DESI by also achieving a better limit of detection for explosives, but still with the need of a more complex setup due to the additional gas supply. For tetryl, the LOD of this technique was $0.25 \mathrm{ng}$. DART-TD-MS [43] is mostly comparable to APLD related to explosives and drugs. While the LOD for (3,4-methylendioxy-methamphetamine) hydrochloride (MDMA) is slightly better than that for DART with $2 \mathrm{ng}$ compared to $10 \mathrm{ng}$, respectively, both systems can detect $2 \mathrm{ng}$ tetryl. Raman spectroscopy in combination with an advanced swab system achieve a LOD of about $5 \mathrm{ng}$ of 2,4-DNT, whereas APLD can measure down to $1.5 \mathrm{ng}$. Moreover, Raman detection limits for cocaine-hydrochloride [44] can be found at about $1 \mu \mathrm{g}$ whereas APLD achieves a LOD of $17 \mathrm{ng}$. According to the author, this high LOD is due to the low analyte cross section and affects all Raman measurements [36]. Ion mobility spectrometry is capable of detecting $350 \mathrm{pg}$ total amount of TNT and $5 \mathrm{ng}$ of cocaine. TD MS allows for the detection of $5 \mathrm{ng}$ of TNT while APLD can detect $500 \mathrm{pg}$. For cocaine [45], a LOD of $388 \mathrm{ng}$ and $2 \mathrm{ng}$ for MDMA [38] is reported.

Table 3. Comparison of LOD of different analytical techniques to APLD for explosives and drugs. DART-TD-MS = Direct analyses in real time-thermal desorption-mass spectrometry.

\begin{tabular}{cccc}
\hline Compared Analytical Technique & Measured Substance & $\begin{array}{c}\text { LOD } \\
\text { Ref. Technique/ng }\end{array}$ & $\begin{array}{c}\text { LOD } \\
\text { APLD/ng }\end{array}$ \\
\hline \multirow{2}{*}{ Raman spectroscopy } & 2,4-DNT & 5 & 1.5 \\
\cline { 2 - 4 } Ion mobility spectrometry & Cocaine HCl & 1000 & 17 \\
\cline { 2 - 4 } & TNT & 0.35 & 0.5 \\
\hline \multirow{2}{*}{ Thermal desorption MS } & Cocaine HCl & 5 & 5 \\
\cline { 2 - 4 } & TNT & 5 & 0.5 \\
\cline { 2 - 4 } Desorption spray ionization & Cocaine HCl & 388 & 17 \\
\cline { 2 - 4 } & MDMA & 2 & 10 \\
\hline Low-temperature plasma probe & TNT & 10 fg & 0.5 \\
\hline \multirow{2}{*}{ DART-TD-MS } & Tetryl & 14 & 20 \\
\cline { 2 - 4 } & Tetryl & 2 & 2 \\
\hline
\end{tabular}

\section{Conclusions}

Within this study, we successfully showed the performance of an improved APLD setup. Various parameters, such as temperature of sampling, desorption area, or desorption head material were modified, while retaining easy handling and flexibility of the system. The novel system showed improved LODs, which are significantly below the original APLD approach and mostly comparable to other atmospheric pressure ionization methods or spectroscopic techniques. The LOD, at laboratory measurements, was $0.5 \mathrm{ng}$ for trinitrotoluene, $17 \mathrm{ng}$ for cocaine hydrochloride, and $6 \mathrm{ng}$ for ketamine, to mention only some of the tested materials.

In particular, the investigation of real-world scenarios exhibited the capabilities of the flexible laser desorption sampling, the soft chemical ionization, and fast ion-trap mass spectrometric detection. 
This allows detection of TNT on bomb shell residues and residues of a new psychoactive substance on the inside of its package.

Furthermore, the system was extended by a unit for the automatized investigation of surfaces by mapping individual pixels. Consequently, the manual laser desorption sampling is no longer required for such surfaces, which improves systematic mapping capabilities.

In summary, APLD with an improved sampling does not require pretreatment of the surface and rapidly exploits a chemical profile. Therefore, it gives indices for conclusions of first responders or at onsite screening operations. By choosing an appropriate transferline length, better LODs or more flexibility can be achieved, depending on the scenario.

For further investigations, cross-sensitivities as well as high throughput behavior would be interesting. In addition, an attempt could be made to use the mapping capability at ambient conditions to scan thin layer chromatography plates, for example, to separate isomeric compounds that are difficult for exclusively MS-based approaches. The use of a more mobile and flexible MS could be beneficial for highly mobile application scenarios if the inherent restrictions in system performance are acceptable. Therefore, APLD in combination with a portable ion trap [46] is promising.

Supplementary Materials: The following are available online at http:/ www.mdpi.com/2076-3417/8/6/933/s1. LabVIEW script for generated heat map, used in Figure 5.

Author Contributions: J.H. and R.R. conceived and designed the experiments; J.H. and R.R. performed the experiments; R.R. analyzed the data; M.P. and T.F. contributed reagents, samples, measurement tools, and expert knowledge for those; R.R. wrote the paper; S.E. and R.Z. contributed significantly to the discussion and revision.

Acknowledgments: This investigation was performed within the SEMFreS project funded by the Federal Ministry of the Interior (BMI) and the Federal Office of Civil Protection and Disaster Assistance, FP406 "SEMFreS". We want to especially thank the German Federal Criminal Police Office (BKA) for providing the samples and the opportunity of a measurement campaign with real samples in Wiesbaden.

Conflicts of Interest: The authors declare no conflict of interest. The founding sponsors had no role in the design of the study; in the collection, analyses, or interpretation of data; in the writing of the manuscript, and in the decision to publish the results.

\section{References}

1. Boumsellek, S.; Alajajian, H.; Chutjian, A. Negative-Ion formation in the explosives RDX, PETN, and TNT by using the reversal electron attachment detection technique. J. Am. Soc. Mass Spectrom. 1992, 3, $243-247$. [CrossRef]

2. Gielsdorf, W. Identifizierung einiger Sprengstoffe mit Hilfe spezieller GC/MS-Techniken, insbesondere der PPNICI-Methode. Fresenius Z. Anal. Chem. 1981, 308, 123-128. [CrossRef]

3. Gillis, R.G. Chemical ionisation mass spectra of explosives. Org. Mass Spectrom. 1974, 9, 359-364. [CrossRef]

4. Pate, C.T.; Mach, M.H. Analysis of explosives using chemical ionization mass spectroscopy. Int. J. Mass Spectrom. Ion Phys. 1978, 26, 267-277. [CrossRef]

5. Wu, Y.-H.; Lin, K.-L.; Chen, S.-C.; Chang, Y.-Z. Integration of GC/EI-MS and GC/NCI-MS for simultaneous quantitative determination of opiates, amphetamines, MDMA, ketamine, and metabolites in human hair. J. Chromatogr. B Anal. Technol. Biomed. Life Sci. 2008, 870, 192-202. [CrossRef] [PubMed]

6. Yinon, J.; McClellan, J.E.; Yost, R.A.; Lifshitz, C. Electrospray ionization tandem mass spectrometry collision-induced dissociation study of explosives in an ion trap mass spectrometer. Rapid Commun. Mass Spectrom. 1997, 11, 1961-1970. [CrossRef]

7. March, R.E. An Introduction to Quadrupole Ion Trap Mass Spectrometry. J. Mass Spectrom. 1997, 32, 351-369. [CrossRef]

8. Schramm, E.; Sklorz, M.; Zimmermann, R.H. Verfahren und Vorrichtung für den Nachweis von Organischen Spurenbestandteilen auf Oberflächen. Patent No. DE102007045361, 22 September 2007.

9. Nilles, J.M.; Connell, T.R.; Stokes, S.T.; Dupont Durst, H. Explosives Detection Using Direct Analysis in Real Time (DART) Mass Spectrometry. Propellants Explos. Pyrotech. 2010, 35, 446-451. [CrossRef]

10. Rowell, F.; Seviour, J.; Lim, A.Y.; Elumbaring-Salazar, C.G.; Loke, J.; Ma, J. Detection of nitro-organic and peroxide explosives in latent fingermarks by DART- and SALDI-TOF-mass spectrometry. Forensic Sci. Int. 2012, 221, 84-91. [CrossRef] [PubMed] 
11. Bridoux, M.C.; Schwarzenberg, A.; Schramm, S.; Cole, R.B. Combined use of direct analysis in real-time/Orbitrap mass spectrometry and micro-Raman spectroscopy for the comprehensive characterization of real explosive samples. Anal. Bioanal. Chem. 2016, 408, 5677-5687. [CrossRef] [PubMed]

12. Chen, C.-H.; Lin, Z.; Garimella, S.; Zheng, L.; Shi, R.; Cooks, R.G.; Ouyang, Z. Development of a mass spectrometry sampling probe for chemical analysis in surgical and endoscopic procedures. Anal. Chem. 2013, 85, 11843-11850. [CrossRef] [PubMed]

13. Justes, D.R.; Talaty, N.; Cotte-Rodriguez, I.; Cooks, R.G. Detection of explosives on skin using ambient ionization mass spectrometry. Chem. Commun. 2007, 2142-2144. [CrossRef] [PubMed]

14. Mirabelli, M.F.; Coviello, G.; Volmer, D.A. Determining fatty acids by desorption/ionization mass spectrometry using thin-layer chromatography substrates. Anal. Bioanal. Chem. 2015, 407, 4513-4522. [CrossRef] [PubMed]

15. Matthews, B.; Walker, G.S.; Kobus, H.; Pigou, P.; Bird, C.; Smith, G. The analysis of dyes in ball point pen inks on single paper fibres using laser desorption ionisation time of flight mass spectrometry (LDI-TOFMS). Forensic Sci. Int. 2011, 209, e26-e30. [CrossRef] [PubMed]

16. Karas, M.; Bachmann, D.; Hillenkamp, F. Influence of the Wavelength in High-Irradiance Ultraviolet Laser Desorption Mass Spectrometry of Organic Molecules. Anal. Chem. 1985, 57, 2935-2939. [CrossRef]

17. Zhang, M.; Shi, Z.; Bai, Y.; Gao, Y.; Hu, R.; Zhao, F. Using molecular recognition of beta-cyclodextrin to determine molecular weights of low-molecular-weight explosives by MALDI-TOF mass spectrometry. J. Am. Soc. Mass Spectrom. 2006, 17, 189-193. [CrossRef] [PubMed]

18. Silina, Y.E.; Koch, M.; Volmer, D.A. The role of physical and chemical properties of Pd nanostructured materials immobilized on inorganic carriers on ion formation in atmospheric pressure laser desorption/ionization mass spectrometry. J. Mass Spectrom. 2014, 49, 468-480. [CrossRef] [PubMed]

19. Compton, L.R.; Reschke, B.; Friend, J.; Powell, M.; Vertes, A. Remote laser ablation electrospray ionization mass spectrometry for non-proximate analysis of biological tissues. Rapid Commun. Mass Spectrom. 2015, 29, 67-73. [CrossRef] [PubMed]

20. Lorenz, M.; Ovchinnikova, O.S.; Kertesz, V.; Van Berkel, G.J. Laser microdissection and atmospheric pressure chemical ionization mass spectrometry coupled for multimodal imaging. Rapid Commun. Mass Spectrom. 2013, 27, 1429-1436. [CrossRef] [PubMed]

21. Roy-Lachapelle, A.; Solliec, M.; Sinotte, M.; Deblois, C.; Sauvé, S. High resolution/accurate mass (HRMS) detection of anatoxin-a in lake water using LDTD-APCI coupled to a Q-Exactive mass spectrometer. Talanta 2015, 132, 836-844. [CrossRef] [PubMed]

22. Morrical, B.D.; Fergenson, D.P.; Prather, K.A. Coupling two-step laser desorption/ionization with aerosol time-of-flight mass spectrometry for the analysis of individual organic particles. J. Am. Soc. Mass Spectrom. 1998, 9, 1068-1073. [CrossRef]

23. Weickhardt, C.; Kaiser, N.; Borsdorf, H. Ion mobility spectrometry of laser desorbed pesticides from fruit surfaces. Int. J. Ion Mobil. Spectrom. 2012, 15, 55-62. [CrossRef]

24. Bermúdez, C.; Cabezas, C.; Mata, S.; Berdakin, M.; Tejedor, J.M.; Alonso, J.L. Analysis of illicit drugs by direct ablation of solid samples. Eur. J. Mass Spectrom. 2015, 21, 775-781. [CrossRef] [PubMed]

25. Morgan, J.S.; Bryden, W.A.; Miragliotta, J.A.; Aamodt, L.C. Improved Detection of Explosive Residues by Laser Thermal Desorption. Johns Hopkins APL Tech. Digest 1999, 20, 389-395.

26. Sabo, M.; Malásková, M.; Matejčík, Š. Laser desorption with corona discharge ion mobility spectrometry for direct surface detection of explosives. Analyst 2014, 139, 5112-5117. [CrossRef] [PubMed]

27. Östmark, H.; Wallin, S.; Ang, H.G. Vapor Pressure of Explosives: A Critical Review. Propellants Explos. Pyrotech. 2012, 37, 12-23. [CrossRef]

28. Dindal, A.B.; Jenkins, R.A.; Buchanan, M.V.; Bayne, C.K. Determination of cocaine and heroin vapor pressures using commercial and illicit samples. Analyst 2000, 125, 1393-1396. [CrossRef] [PubMed]

29. Li, L.; Lubman, D.M. Pulsed laser desorption method for volatilizing thermally labile molecules for supersonic jet spectroscopy. Rev. Sci. Instrum. 1988, 59, 557. [CrossRef]

30. Ehlert, S.; Walte, A.; Zimmermann, R. Ambient pressure laser desorption and laser-induced acoustic desorption ion mobility spectrometry detection of explosives. Anal. Chem. 2013, 85, 11047-11053. [CrossRef] [PubMed] 
31. Ehlert, S.; Hölzer, J.; Rittgen, J.; Pütz, M.; Schulte-Ladbeck, R.; Zimmermann, R. Rapid on-site detection of explosives on surfaces by ambient pressure laser desorption and direct inlet single photon ionization or chemical ionization mass spectrometry. Anal. Bioanal. Chem. 2013, 405, 6979-6993. [CrossRef] [PubMed]

32. Lamb, A.; Tollefson, E.L. Catalytic reduction of nitric oxide in low concentration high velocity gas streams. Can. J. Chem. Eng. 1973, 51, 191-200. [CrossRef]

33. Ford, L.T.; Berg, J.D. 1-Adamantylamine a simple urine marker for screening for third generation adamantyl-type synthetic cannabinoids by ultra-performance liquid chromatography tandem mass spectrometry. Ann. Clin. Biochem. 2016, 53, 640-646. [CrossRef] [PubMed]

34. So, P.-K.; Ng, T.-T.; Wang, H.; Hu, B.; Yao, Z.-P. Rapid detection and quantitation of ketamine and norketamine in urine and oral fluid by wooden-tip electrospray ionization mass spectrometry. Analyst 2013, 138, 2239-2243. [CrossRef] [PubMed]

35. Asada, A.; Doi, T.; Tagami, T.; Takeda, A.; Satsuki, Y.; Kawaguchi, M.; Nakamura, A.; Sawabe, Y. Cannabimimetic activities of cumyl carboxamide-type synthetic cannabinoids. Forensic Toxicol. 2017, 31, 44. [CrossRef]

36. Gong, Z.; Du, H.; Cheng, F.; Wang, C.; Wang, C.; Fan, M. Fabrication of SERS swab for direct detection of trace explosives in fingerprints. ACS Appl. Mater. Interfaces 2014, 6, 21931-21937. [CrossRef] [PubMed]

37. Sabo, M.; Malásková, M.; Matejčík, Š. Ion mobility spectrometry-mass spectrometry studies of ion processes in air at atmospheric pressure and their application to thermal desorption of 2,4,6-trinitrotoluene. Plasma Sources Sci. Technol. 2014, 23, 15025. [CrossRef]

38. Forbes, T.P.; Staymates, M.; Sisco, E. Broad spectrum infrared thermal desorption of wipe-based explosive and narcotic samples for trace mass spectrometric detection. Analyst 2017, 142, 3002-3010. [CrossRef] [PubMed]

39. Zhao, Q.; Liu, J.; Wang, B.; Zhang, X.; Huang, G.; Xu, W. Rapid screening of explosives in ambient environment by aerodynamic assisted thermo desorption mass spectrometry. J. Mass Spectrom. 2017, 52, 1-6. [CrossRef] [PubMed]

40. Green, F.M.; Salter, T.L.; Stokes, P.; Gilmore, I.S.; O'Connor, G. Ambient mass spectrometry: Advances and applications in forensics. Surf. Interface Anal. 2010, 42, 347-357. [CrossRef]

41. Stojanovska, N.; Kelly, T.; Tahtouh, M.; Beavis, A.; Fu, S. Analysis of amphetamine-type substances and piperazine analogues using desorption electrospray ionisation mass spectrometry. Rapid Commun. Mass Spectrom. 2014, 28, 731-740. [CrossRef] [PubMed]

42. Garcia-Reyes, J.F.; Harper, J.D.; Salazar, G.A.; Charipar, N.A.; Ouyang, Z.; Cooks, R.G. Detection of explosives and related compounds by low-temperature plasma ambient ionization mass spectrometry. Anal. Chem. 2011, 83, 1084-1092. [CrossRef] [PubMed]

43. Sisco, E.; Forbes, T.P.; Staymates, M.E.; Gillen, G. Rapid Analysis of Trace Drugs and Metabolites Using a Thermal Desorption DART-MS Configuration. Anal. Methods: Adv. Methods Appl. 2016, 8, 6494-6499. [CrossRef] [PubMed]

44. Sägmüller, B.; Schwarze, B.; Brehm, G.; Trachta, G.; Schneider, S. Identification of illicit drugs by a combination of liquid chromatography and surface-enhanced Raman scattering spectroscopy. J. Mol. Struct. 2003, 661-662, 279-290. [CrossRef]

45. Demoranville, L.T.; Brewer, T.M. Ambient pressure thermal desorption ionization mass spectrometry for the analysis of substances of forensic interest. Analyst 2013, 138, 5332-5337. [CrossRef] [PubMed]

46. Gao, L.; Song, Q.; Patterson, G.E.; Cooks, R.G.; Ouyang, Z. Handheld rectilinear ion trap mass spectrometer. Anal. Chem. 2006, 78, 5994-6002. [CrossRef] [PubMed]

(C) 2018 by the authors. Licensee MDPI, Basel, Switzerland. This article is an open access article distributed under the terms and conditions of the Creative Commons Attribution (CC BY) license (http:/ / creativecommons.org/licenses/by/4.0/). 